\title{
ARTICLE
}

Epidemiology

\section{Metformin use and risk of gastric adenocarcinoma in a Swedish population-based cohort study}

\author{
Jiaojiao Zheng ${ }^{1}$, Shao-Hua Xie ${ }^{1}$, Giola Santoni ${ }^{1}$ and Jesper Lagergren ${ }^{1,2}$
}

\begin{abstract}
BACKGROUND: Whether or not the use of metformin decreases the risk of gastric adenocarcinoma is unclear. METHODS: This was a population-based cohort study in 2005-2015. Associations between metformin use and gastric non-cardia and cardia adenocarcinomas were examined within two cohorts; a diabetes cohort of participants using anti-diabetes medications, and a matched cohort of common-medication users, where metformin non-users were frequency matched (10:1) with metformin users for sex and age. Multivariable Cox proportional hazard regression analyses provided hazard ratios (HR) and $95 \%$ confidence intervals (Cl), adjusting for sex, age, calendar year, comorbidity, Helicobacter pylori eradication treatment, use of non-steroidal antiinflammatory drugs or aspirin and use of statins.

RESULTS: During the follow-up for a median of 5.8 years, $892(0.1 \%)$ participants in the diabetes cohort and $6395(0.1 \%)$ participants in the matched cohort of common-medication users developed gastric adenocarcinoma. Metformin users had no significantly decreased risk of gastric non-cardia adenocarcinoma (diabetes cohort: HR 0.93, 95\% Cl 0.78-1.12; matched cohort: HR 1.30, 95\% Cl 1.18-1.42) or cardia adenocarcinoma (diabetes cohort: HR 1.49, 95\% Cl 1.09-2.02; matched cohort: $\mathrm{HR} 1.58,95 \% \mathrm{Cl}$ 1.38-1.81) compared with non-users in both cohorts.

CONCLUSIONS: This cohort study with $<10$ years of follow-up suggests metformin use may not prevent gastric adenocarcinoma.
\end{abstract}

British Journal of Cancer (2019) 121:877-882; https://doi.org/10.1038/s41416-019-0598-z

\section{BACKGROUND}

Gastric cancer, with adenocarcinoma as the predominant (>95\%) histological type, is the 6th most common cancer and 3rd leading cause of cancer death worldwide. ${ }^{1}$ The major anatomical subtypes, non-cardia and cardia adenocarcinomas have distinct aetiology. Helicobacter pylori $(H$. pylori) infection is the main known risk factor for non-cardia adenocarcinoma, while obesity and gastro-oesophageal reflux disease are the main known risk factors for cardia adenocarcinoma. ${ }^{2,3}$ Both non-cardia and cardia adenocarcinoma have a poor prognosis with a 5 -year overall survival rate $<30 \%$ in most countries, which highlights the need to identify preventive measures for high-risk groups. ${ }^{4}$

Metformin is a first-line oral glucose-lowering medication, widely used in the treatment of type 2 diabetes. Metformin may decrease the risk of some cancer types, ${ }^{5}$ especially cancer of the breast, liver, colon and rectum. ${ }^{6-8}$ Possible anti-carcinogenic mechanisms of metformin include direct activation of the $5^{\prime}$ adenosine monophosphate-activated protein kinase (AMPK) pathway and indirect effects from lowering the blood glucose and insulin levels. ${ }^{9}$ Studies have shown that metformin can inhibit gastric cancer growth in mice, ${ }^{10}$ decrease the invasion and migration of gastric cancer cells ${ }^{11}$ and inhibit the carcinogenic properties of gastric cancer stem cells. ${ }^{12}$ However, evidence from human studies regarding the role of metformin in the prevention of gastric adenocarcinoma is limited, and the results are inconsistent. Most available studies come from Asian populations and do not separately investigate gastric non-cardia and cardia adenocarcinomas. ${ }^{13}$

This study aimed to test the hypothesis that use of metformin decreases the risk of gastric non-cardia and cardia adenocarcinoma in a Western population.

\section{METHODS}

Source cohort

This study was based on a nationwide population-based cohort, entitled the Swedish Prescribed Drugs and Health Cohort (SPREDH). The details of this cohort have been described elsewhere. ${ }^{14}$ In brief, SPREDH includes $8,421,115$ Swedish residents with dispensed records of commonly prescribed medications from 1st July 2005 to 31st December 2015. These commonly prescribed medications were sex hormones and modulators of the genital system; drugs for the treatment of diabetes; drugs used against benign prostatic hypertrophy; hormones, hormone antagonists and related agents in antineoplastic and immunemodulating therapy; diuretics; lipid modifying agents; antiinflammatory agents, analgesics and platelet-aggregation inhibitors; and drugs for peptic ulcer and gastro-oesophageal reflux disease. The participants of SPREDH accounted for $~ 51 \%$ of the entire Swedish population in 2005. ${ }^{14}$ The SPREDH also contains relevant health data of the participants, retrieved from four nationwide health data registries in Sweden: The Prescribed Drug

\footnotetext{
${ }^{1}$ Upper Gastrointestinal Surgery, Department of Molecular medicine and Surgery, Karolinska Institutet, Karolinska University Hospital, Stockholm, Sweden and ${ }^{2}$ School of Cancer and Pharmaceutical Sciences, King's College London, London, UK

Correspondence: Shao-Hua Xie (shaohua.xie@ki.se)
}

Received: 1 July 2019 Revised: 17 September 2019 Accepted: 19 September 2019

Published online: 8 October 2019 
Registry, Cancer Registry, Patient Registry and the Cause of Death Registry.

The Prescribed Drug Registry records individual-level data on all prescribed and dispensed drugs in Sweden since 1st July $2005 .{ }^{15}$ It covers $84 \%$ of the total drug sales in Sweden, the remaining part is medications sold over-the-counter or used in hospitals. Every year, $\sim 66 \%$ of the Swedish population had at least one record in the Prescribed Drug Registry. ${ }^{15,16}$

The Cancer Registry records data on all cancer diagnoses in Sweden from 1958 onwards. The completeness and positive predictive value of the diagnosis gastric adenocarcinoma are 98 and $96 \%$, respectively. ${ }^{17}$

The Patient Registry contains data on diagnoses and surgical and medical procedures in hospitals since 1987 and from specialist outpatient care since $2001 .^{18}$ The positive predictive value of in-hospital diagnoses is in the range of $85-95 \% .{ }^{19}$

The Cause of Death Registry records dates and causes of death of all Swedish residents since 1952. The completeness of both date of death and causes of death data is at least $99 \% .^{20}$

The linkages of individuals' data between these registries were enabled by the 10-digit unique personal identity number assigned to each Swedish resident upon birth or immigration.

\section{Study design}

This was a population-based cohort study from 1st July 2005 to 31st December 2015. All individuals in SPREDH during this study period were potentially eligible for the study. The three exclusion criteria were: (1) previous cancer diagnosis (other than nonmelanoma skin cancer) before the cohort entry (identified by the 7th edition of the International Classification of Diseases [ICD-7] codes 140-209, excluding 191 in the Cancer Registry); (2) gastrectomy conducted before the cohort entry (identified by the Nordic Medico-Statistical Committee Classification of Surgical Procedures codes 4411-4420, 4422, 4424-4426, 4429, 4430, 4432, 4434 and 4435 before 1997 and JDC and JDD from 1997 onwards in the Patient Registry); and (3) age below 18 years at the cohort entry.

\section{Two study cohorts}

Two cohorts were identified from the source cohort, a 'diabetes cohort' and a 'matched cohort of common-medication users'.

The diabetes cohort. Individuals in SPREDH were included in the diabetes cohort based on their history of using anti-diabetic medications, defined by any dispensed record of anti-diabetic medication(s) (represented by the Anatomical Therapeutic Chemical (ATC) codes $A 10 A$ and $A 10 B$ in the Prescribed Drug Registry) during the study period. The exposed group was users of metformin, with or without other anti-diabetic medications, represented by the ATC codes A10BA02, A10BD02, A10BD03, A10BD05, A10BD07, A10BD08, A10BD10, A10BD11, A10BD13, A10BD14, A10BD15, A10BD16, A10BD17, A10BD18, A10BD20 and $A 10 B D 22$ in the Prescribed Drug Registry. The unexposed group consisted of users of anti-diabetic medication(s) other than metformin, i.e., metformin non-users. The entry date into the diabetes cohort was the first dispensation date of any anti-diabetic medication. To exclude individuals using anti-diabetic medications for other indications than diabetes, we excluded women with diagnoses of gestational diabetes (represented by the Swedish ICD10 codes 024.4 and O24.9) or polycystic ovarian syndrome (represented by the Swedish ICD-10 code E28.2) in the Patient Registry. However, if a woman with polycystic ovarian syndrome had a first dispensation record of anti-diabetic medication other than metformin, or a later dispensation record of a second anti-diabetic medication, she would be included at the first dispensation date of any anti-diabetic medication(s) other than metformin. In the latter case, the woman was regarded exposed at the cohort entry. The exposure status was allowed to change, i.e., an unexposed participant became exposed at the first purchase of metformin.
The matched cohort of common-medication users. This cohort was also derived from SPREDH. The exposed group was metformin users, defined by those who had any dispensed record of metformin in the Prescribed Drug Registry (details above). However, women with any diagnosis of gestational diabetes or polycystic ovarian syndrome were not excluded from the exposed group. The entry date of the metformin users was the first dispensation date of metformin. For each metformin user, ten non-users of metformin were randomly sampled from SPREDH as comparison participants, using frequency matching by age ( \pm 1year) and sex. Thus, the comparison participants entered the cohort on the same date as their matched metformin users. The exposure status was allowed to change also in this cohort.

\section{Study outcomes}

Newly diagnosed gastric adenocarcinomas during the study period were identified from the Cancer Registry by the ICD-7 code 151 combined with the histology code 096 for adenocarcinoma in the WHO/HS/CANC/24.1 classification. Gastric non-cardia adenocarcinoma (ICD-7 code 151, excluding 151.1, and histology code 096) and cardia adenocarcinoma (ICD-7 code 151.1 and histology code 096) were the outcomes. All cohort members were followed up until the occurrence of any gastric adenocarcinoma, death or the end of the study (December 31st, 2015), whichever occurred first.

\section{Potential confounders}

Seven factors were considered as potential confounders, for their possible associations with both metformin use and risk of gastric adenocarcinoma: (1) sex (male or female), (2) age (continuous), (3) calendar year (categorised as 2005, 2006-2010 or 2011-2015), (4) comorbidity (Charlson comorbidity index, categorised as 0,1 or $\geq 2$ ), (5) H. pylori eradication treatment (yes or no), (6) use of non-steroidal anti-inflammatory drugs (NSAIDs) or aspirin (yes or no) and (7) use of statins (yes or no).

Comorbidities (excluding diabetes) diagnosed within 10 years before the cohort entry were searched in the Patient Registry, and were handled using the well-validated Charlson comorbidity index. ${ }^{21}$ While no direct data on $H$. pylori infection were available, a dispensed record of standard $H$. pylori eradication packages (ATC code A02BD in the Prescribed Drug Registry) was used to represent clinically diagnosed $H$. pylori infection. These $H$. pylori eradication packages account for $85 \%$ of the $H$. pylori eradication therapy in Sweden. ${ }^{22} \mathrm{H}$. pylori eradication treatment was treated as a time-varying variable. Use of NSAIDs or aspirin ${ }^{23}$ and use of statins ${ }^{24}$ were also identified by the ATC codes in the Prescribed Drug Registry (for NSAIDs and aspirin: M01A, N02BA, B01AC06, C10BX01, C10BX02, C10BX04, C10BX05, C10BX06, C10BX08, C10BX12, C07FX02, C07FX03 and C07FX04; for statins: C10AA and $\mathrm{C} 10 \mathrm{~B}$ ) and were categorised as binary variables (yes or no). To be identified as a user of these medications, an individual had to have at least two dispensation records within the first year after cohort entry.

\section{Statistical analysis}

Multivariable Cox proportional hazards regressions were used to estimate the hazard ratios (HR) with $95 \%$ confidence intervals $(\mathrm{Cl})$ of gastric adenocarcinomas comparing metformin users with nonusers in both the diabetes cohort and the matched cohort of common-medication users. The risks of gastric non-cardia and cardia adenocarcinomas were analysed combined and separately in both cohorts. Two models were applied, a crude model (without any adjustment) and a model with adjustment for the seven potential confounders presented and categorised above.

Six sub-group analyses were performed specifically for the risk of gastric non-cardia adenocarcinoma: (1) A dose-response analysis was examined among all users of metformin only. Metformin use was categorised into three levels according to the 
Metformin use and risk of gastric adenocarcinoma in a Swedish...

Table 1. Characteristics of the study participants in the diabetes cohort and the matched cohort of common-medication users, numbers (\%)

\begin{tabular}{|c|c|c|c|c|}
\hline & \multicolumn{2}{|l|}{ Diabetes cohort } & \multicolumn{2}{|l|}{ Matched cohort } \\
\hline Total & $334,506(61.5)$ & $209,624(38.5)$ & $411,413(9.1)$ & $4,114,130(90.9)$ \\
\hline \multicolumn{5}{|l|}{ Sex } \\
\hline Men & $196,721(58.8)$ & $120,048(57.3)$ & $239,256(58.2)$ & $2,392,560(58.2)$ \\
\hline Women & $137,785(41.2)$ & $89,576(42.7)$ & $172,157(41.8)$ & $17,211,570(41.8)$ \\
\hline 2005 & $102,834(30.7)$ & $142,293(67.9)$ & $127,136(30.9)$ & $1,271,360(30.9)$ \\
\hline 2006-2010 & $111,199(33.2)$ & $41,432(19.7)$ & $146,175(35.5)$ & $1,461,750(35.5)$ \\
\hline $2011-2015$ & $120,473(36.0)$ & $25,899(12.4)$ & $138,102(33.6)$ & $1,381,020(33.6)$ \\
\hline \multicolumn{5}{|l|}{ Charlson comorbidity $^{\mathrm{b}}$} \\
\hline 0 & $250,635(74.9)$ & $135,583(64.7)$ & $303,840(73.9)$ & $3,265,518(79.4)$ \\
\hline No & $175,589(52.5)$ & $109,565(52.3)$ & $247,988(60.3)$ & $3,048,169(74.1)$ \\
\hline Yes & $158,920(47.5)$ & $100,059(47.7)$ & $163,425(39.7)$ & $1,065,961(25.9)$ \\
\hline \multicolumn{5}{|l|}{ Use of statin c } \\
\hline No & $162,671(48.6)$ & $129,555(61.8)$ & $22,841(54.2)$ & $3,377,102(82.1)$ \\
\hline Yes & $171,835(51.4)$ & $80,069(38.2)$ & $188,572(45.8)$ & $737,028(17.9)$ \\
\hline \multicolumn{5}{|l|}{ Helicobacter pylori eradication } \\
\hline No & $324,885(97.1)$ & $205,024(97.8)$ & $399,781(97.2)$ & $4,027,949(97.9)$ \\
\hline Yes, before entry & $3515(1.1)$ & $762(0.4)$ & $4238(1.0)$ & $33,813(0.8)$ \\
\hline Yes, after entry & $6106(1.8)$ & $3838(1.8)$ & $7394(1.8)$ & $52,368(1.3)$ \\
\hline \multicolumn{5}{|l|}{ Death during follow-up } \\
\hline No & $282,110(84.3)$ & $133,819(63.8)$ & $340,543(82.8)$ & $3,590,316(87.3)$ \\
\hline
\end{tabular}

total defined daily dose (DDD) in the first year after the first known date of dispensation: $<175$ DDDs, 175-300 DDDs and > 300 DDDs. $P$-value for trend was tested by treating the dose as a continuous variable based on the median values of each category. The remaining five sub-group analyses were performed only in the diabetes cohort; (2) stratified analyses by sex, age (above and below the median) and duration of follow-up ( $\leq 3$ years, $3-6$ years and $\geq 6$ years); (3) sensitivity analyses, excluding individuals with less than 1 year of follow-up; (4) sensitivity analyses comparing non-users with prevalent users of metformin, with prevalent users being those who had at least one dispensation of metformin within the first year after the Prescribed Drug Registry came into use, i.e., between 2005 July 1st and 2006 June 30th; (5) sensitivity analyses restricted to participants with a history of $H$. pylori eradication treatment and (6) sensitivity analyses restricted to participants with diagnoses of type 2 diabetes throughout the follow-up (represented by the Swedish ICD-10 code E11 in the Patient Registry).

The proportional hazard assumption for the Cox regression analyses was tested by evaluating whether the scaled Schoenfeld residuals on time were constant over time. The assumption was met for all analyses. In the diabetes cohort, the timeline in the Cox regression was attained age, while in the matched cohort the timeline was time since entry into the study. A biostatistician (GS) was responsible for the data management and statistical analyses using the statistical software Stata (Release 15, StataCorp, College Station, TX).

\section{RESULTS}

Participants in the diabetes cohort

The diabetes cohort included 544,130 participants. At the cohort entry, 334,506 (61.5\%) of these were metformin users, and 209,624 $(38.5 \%)$ were non-users of metformin. A total of $72,643(13.4 \%)$ non-users at baseline started using metformin during the followup. The number of person-years exposed to metformin was $2,432,273$, and the number of person-years not exposed to metformin was 998,884 . Compared with non-users, metformin users had less comorbidity, a higher proportion of users of statins, a higher proportion with $H$. pylori eradication therapy and lower overall mortality (Table 1). During the follow-up for a median of 5.8 years (interquartile range 2.3-10.0), 892 (0.1\%) participants developed gastric adenocarcinoma.

Participants in the matched cohort of common-medication users The matched cohort of common-medication users included $4,525,543$ participants. Of these, $411,413(9.1 \%)$ were metformin users and 4,114,130 (90.9\%) were age-matched and sexmatched non-users of metformin. The number of person-years exposed to metformin was $2,457,824$, and the number of person-years not exposed to metformin was 23,912,966. Compared with non-users, metformin users had more comorbidity, higher proportions of users of NSAIDs or aspirin and statins and higher overall mortality, whereas the proportion with $H$. pylori eradication therapy was similar in users and non-users 
Table 2. Risk of total, non-cardia and cardia gastric adenocarcinomas in metformin users compared with non-users in the diabetes cohort and the matched cohort of common-medication users

\begin{tabular}{|c|c|c|c|}
\hline & $\begin{array}{l}\text { Number } \\
\text { of cases }\end{array}$ & $\begin{array}{l}\text { Crude HR } \\
(95 \% \mathrm{Cl})\end{array}$ & $\begin{array}{l}\text { Adjusted HR } \\
(95 \% \mathrm{CI})^{\mathrm{a}}\end{array}$ \\
\hline \multicolumn{4}{|l|}{ Total adenocarcinoma } \\
\hline \multicolumn{4}{|l|}{ Diabetes cohort } \\
\hline Non-users & 233 & Reference & Reference \\
\hline Metformin users & 659 & $0.99(0.85-1.15)$ & $1.08(0.92-1.26)$ \\
\hline \multicolumn{4}{|l|}{ Matched cohort } \\
\hline Non-users & 5606 & Reference & Reference \\
\hline Metformin users & 789 & $1.37(1.26-1.48)$ & $1.38(1.26-1.50)$ \\
\hline \multicolumn{4}{|c|}{ Non-cardia adenocarcinoma } \\
\hline \multicolumn{4}{|l|}{ Diabetes cohort } \\
\hline Non-users & 173 & Reference & Reference \\
\hline Metformin users & 421 & $0.88(0.73-1.05)$ & $0.93(0.78-1.12)$ \\
\hline \multicolumn{4}{|l|}{ Matched cohort } \\
\hline Non-users & 4061 & Reference & Reference \\
\hline Metformin users & 533 & $1.28(1.16-1.41)$ & $1.30(1.18-1.42)$ \\
\hline \multicolumn{4}{|c|}{ Cardia adenocarcinoma } \\
\hline \multicolumn{4}{|l|}{ Diabetes cohort } \\
\hline Non-users & 60 & Reference & Reference \\
\hline Metformin users & 238 & $1.30(0.97-1.74)$ & $1.49(1.09-2.02)$ \\
\hline \multicolumn{4}{|l|}{ Matched cohort } \\
\hline Non-users & 1545 & Reference & Reference \\
\hline Metformin users & 256 & $1.61(1.39-1.86)$ & $1.58(1.38-1.81)$ \\
\hline \multicolumn{4}{|c|}{$\begin{array}{l}\text { HR hazard ratio, } \mathrm{Cl} \text { confidence interval } \\
\text { aAdjusted for sex, age, calendar year, use of non-steroidal anti-inflamma- } \\
\text { tory drugs or aspirin, use of statins, Charlson comorbidity index and } \\
\text { Helicobacter pylori eradication treatment }\end{array}$} \\
\hline
\end{tabular}

of metformin (Table 1). During the follow-up for a median of 5.8 years (interquartile range 2.8-9.4 years), 6395 (0.1\%) participants developed gastric adenocarcinoma.

Risk of total gastric adenocarcinoma

In the diabetes cohort, metformin use was not associated with any decreased risk of gastric adenocarcinoma (adjusted HR 1.08, 95\% $\mathrm{Cl}$ 0.92-1.26). Similarly, the results of the matched cohort of common-medication users revealed no decreased risk of total gastric adenocarcinoma in metformin users compared with nonusers, but rather an increased risk (adjusted HR 1.38, 95\% Cl 1.26-1.50) (Table 2).

Risk of gastric non-cardia adenocarcinoma In the diabetes cohort, use of metformin did not influence the risk of gastric non-cardia adenocarcinoma (adjusted HR 0.93, 95\% $\mathrm{Cl}$ 0.78-1.12). In the matched cohort of common-medication users, the risk of gastric non-cardia adenocarcinoma was not decreased, but rather increased, among metformin users compared with nonusers (adjusted HR 1.30, 95\% Cl 1.18-1.42) (Table 2).

In the sub-group analyses, no dose-response relation for metformin use and the risk of non-cardia adenocarcinoma was found. Compared with participants who used a low dose $(<175$ DDD) of metformin, those who used a moderate dose (175-300 DDD) or a high dose (>300 DDD) did not have any reduced risk of gastric non-cardia adenocarcinoma (Table 3). In the stratified analyses of the diabetes cohort, metformin use was not associated with any decreased risk of gastric non-cardia adenocarcinoma in any of the sex or age groups, or in different durations of follow-up
Table 3. Dose-response analysis for the risk of gastric non-cardia adenocarcinoma among metformin users

\begin{tabular}{llll}
\hline Dosage $^{\mathrm{a}}$ & $\begin{array}{l}\text { Number } \\
\text { of cases }\end{array}$ & $\begin{array}{l}\text { Crude HR } \\
(95 \% \mathrm{Cl})\end{array}$ & $\begin{array}{l}\text { Adjusted HR } \\
(95 \% \mathrm{Cl})^{\mathrm{b}}\end{array}$ \\
\hline $\begin{array}{l}\text { Less than 175 DDD } \\
175-300 \text { DDD }\end{array}$ & 122 & Reference & Reference \\
$\begin{array}{l}\text { More than } \\
300 \text { DDD }\end{array}$ & 147 & $0.99(0.77-1.29)$ & $1.02(0.77-1.34)$ \\
$P$ for trend & 0.887 & 0.904 \\
\hline $\begin{array}{l}H R \text { hazard ratio, Cl confidence interval } \\
\text { a'Defined as total Defined Daily Dose (DDD) used in the first year after the } \\
\text { first dispensation of metformin } \\
\text { bAdjusted for sex, age, calendar year, use of non-steroidal anti-inflamma- } \\
\text { tory drugs or aspirin, use of statins, Charlson comorbidity index and } \\
\text { Helicobacter pylori eradication treatment }\end{array}$ \\
\hline
\end{tabular}

(Table 4). In the sensitivity analyses restricted to prevalent metformin users, restricted to participants who were followed up for at least 1 year, restricted to participants who had received H. pylori eradication therapy, and restricted to participants with diagnoses of type 2 diabetes, no substantial changes in risk estimates were found (Table 4).

Risk of gastric cardia adenocarcinoma

Compared with metformin non-users, the risk estimates of gastric cardia adenocarcinoma were not decreased, but rather increased, among metformin users in the diabetes cohort (adjusted HR 1.49, 95\% Cl 1.09-2.02) and in the matched cohort of common-medication users (adjusted HR 1.58, 95\%Cl 1.38-1.81) (Table 2).

\section{DISCUSSION}

This study indicates that metformin use does not decrease the risk of gastric non-cardia or cardia adenocarcinoma in a Western population during the follow-up for a median of 6 years.

Strengths of the study include the population-based cohort design, the use of high-quality data with nationwide coverage and the complete follow-up. This study is also the first to analyse gastric non-cardia and cardia adenocarcinoma separately. Several potential confounders were taken into account, including $H$. pylori infection and use of certain medications that may affect the risk of gastric adenocarcinoma. Yet, a limitation of the study was the lack of information on some other potential confounders, particularly obesity. Obesity is associated with an increased risk of gastric cardia adenocarcinoma, and diabetes patients are generally more obese than non-diabetic people. ${ }^{25}$ Besides, diabetes patients using metformin have been reported to have even higher body mass index than diabetes patients treated by other medications. ${ }^{26}$ Thus, the increased risk estimates of gastric cardia adenocarcinoma among metformin users in this study might well be explained by confounding by obesity. However, confounding by obesity should not be a problem in the analyses of gastric non-cardia adenocarcinoma, because obesity is not a risk factor for gastric non-cardia adenocarcinoma. ${ }^{27,28}$ This was the rationale for conducting the post hoc sub-group analyses for gastric non-cardia adenocarcinoma only. Another limitation was the relatively short follow-up (maximum 10 years), because data on drug use before July 2005 (when the Prescribed Drug Registry started) were not available. It is possible that any protective effect of metformin is limited in the very early stage of gastric carcinogenesis, and therefore may be missed by the current study. Thus, the risks of gastric noncardia and cardia adenocarcinoma in relation to the use of 
Table 4. Sub-group analyses of the risk of gastric non-cardia adenocarcinoma in metformin users compared with non-users in the diabetes cohort

\begin{tabular}{|c|c|c|c|}
\hline & $\begin{array}{l}\text { Number } \\
\text { of cases }\end{array}$ & $\begin{array}{l}\text { Crude HR } \\
(95 \% \mathrm{CI})\end{array}$ & $\begin{array}{l}\text { Adjusted HR } \\
(95 \% \mathrm{Cl})^{\mathrm{a}}\end{array}$ \\
\hline \multicolumn{4}{|l|}{ Stratified analyses } \\
\hline \multicolumn{4}{|l|}{ Sex } \\
\hline \multicolumn{4}{|l|}{ Men } \\
\hline Non-users & 103 & Reference & Reference \\
\hline Metformin users & 258 & $0.91(0.72-1.15)$ & $0.95(0.75-1.21)$ \\
\hline \multicolumn{4}{|l|}{ Women } \\
\hline Non-users & 70 & Reference & Reference \\
\hline Metformin users & 163 & $0.85(0.64-1.12)$ & $0.90(0.68-1.20)$ \\
\hline \multicolumn{4}{|l|}{ Age } \\
\hline \multicolumn{4}{|l|}{$\leq 60$} \\
\hline Non-users & 23 & Reference & Reference \\
\hline Metformin users & 65 & $0.90(0.56-1.44)$ & $0.94(0.58-1.51)$ \\
\hline \multicolumn{4}{|c|}{ 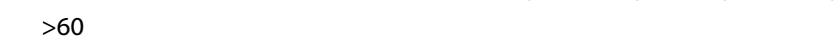 } \\
\hline Non-users & 150 & Reference & Reference \\
\hline Metformin users & 356 & $0.88(0.72-1.06)$ & $0.93(0.76-1.13)$ \\
\hline \multicolumn{4}{|l|}{ Follow-up } \\
\hline \multicolumn{4}{|l|}{$0-3$ years } \\
\hline Non-users & 82 & Reference & Reference \\
\hline Metformin users & 160 & $0.90(0.69-1.18)$ & $1.01(0.76-1.33)$ \\
\hline \multicolumn{4}{|l|}{$3-6$ years } \\
\hline Non-users & 54 & Reference & Reference \\
\hline Metformin users & 129 & $0.79(0.58-1.08)$ & $0.84(0.61-1.16)$ \\
\hline \multicolumn{4}{|l|}{$\geq 6$ years } \\
\hline Non-users & 37 & Reference & Reference \\
\hline Metformin users & 132 & $1.01(0.70-1.45)$ & $1.03(0.71-1.49)$ \\
\hline \multicolumn{4}{|c|}{ Sensitivity analysis $1(\mathrm{~N}=355,461)^{\mathrm{b}}$} \\
\hline Non-users & 173 & Reference & Reference \\
\hline $\begin{array}{c}\text { Metformin } \\
\text { prevalent users }\end{array}$ & 250 & $0.92(0.76-1.11)$ & $0.92(0.75-1.13)$ \\
\hline \multicolumn{4}{|c|}{ Sensitivity analysis $2(\mathrm{~N}=495,822)^{\mathrm{c}}$} \\
\hline Non-users & 137 & Reference & Reference \\
\hline Metformin users & 374 & $0.91(0.75-1.11)$ & $0.95(0.78-1.17)$ \\
\hline \multicolumn{4}{|c|}{ Sensitivity analysis $3(\mathrm{~N}=14,221)^{\mathrm{d}}$} \\
\hline Non-users & 13 & Reference & Reference \\
\hline Metformin users & 55 & $1.11(0.61-2.02)$ & $1.13(0.61-2.06)$ \\
\hline \multicolumn{4}{|c|}{ Sensitivity analysis $4(N=206,769)^{\mathrm{e}}$} \\
\hline Non-users & 52 & Reference & Reference \\
\hline Metformin users & 219 & $0.92(0.68-1.25)$ & $0.94(0.69-1.28)$ \\
\hline
\end{tabular}

$H R$ hazard ratio, $\mathrm{Cl}$ confidence interval

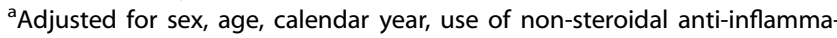
tory drugs or aspirin, use of statins, Charlson comorbidity index and Helicobacter pylori eradication treatment

${ }^{\mathrm{b}}$ Restricted to prevalent metformin users as the exposed group

${ }^{c}$ Restricted to participants who were followed up for at least 1 year

${ }^{d}$ Restricted to participants who had received Helicobacter pylori eradication therapy

e Restricted to participants who had diagnoses of type 2 diabetes only throughout the follow-up

metformin in our study may only reflect the effect of metformin during a limited observation period.

Previous studies examining metformin use in relation to the risk of gastric adenocarcinoma are few, and have provided inconsistent results. ${ }^{29-32}$ All these studies were performed within diabetes populations, comparing metformin users with those either using other anti-diabetic medications or sulfonylurea. $^{29-36}$ Some studies, mostly from Asian populations, have indicated a decreased risk of gastric adenocarcinoma in metformin users, with HRs ranging from 0.83 to $0.45 .29,32,33,36$ A recent cohort study from Hong Kong in diabetes patients who had received $H$. pylori eradication therapy found a reduced risk of gastric adenocarcinoma in metformin users (HR $0.49,95 \% \mathrm{Cl}$ $0.24-0.98){ }^{33}$ which was inconsistent with our results. This study adds to the limited body of literature in Western populations and the lack of any protective effect is supported by two other studies from Western populations, one from the United States and the other from Italy. ${ }^{31,35}$

A novel aspect of this study was the analyses in the matched cohort of common-medication users, besides a diabetes cohort. While no association between metformin use and risk of gastric non-cardia adenocarcinoma was found in the diabetes cohort, it is interesting that an increased risk of gastric non-cardia adenocarcinoma was suggested among metformin users compared with non-users in this matched cohort. This difference indicates a role of diabetes or diabetes-related factors in the aetiology of gastric adenocarcinoma, which highlight a need for research on this topic. However, the existing literature has provided inconclusive evidence regarding the effects of diabetes on the risks of gastric adenocarcinoma and gastric cardia adenocarcinoma. ${ }^{37-42}$

In conclusion, this large and population-based cohort study in Sweden does not support the hypothesis that use of metformin decreases the risk of gastric non-cardia or cardia adenocarcinoma within the initial years of follow-up.

\section{AUTHOR CONTRIBUTIONS}

All authors designed the study. J.L. and S.X. collected the data for the study. G.S. analysed the data. J.Z. interpreted the results and drafted the paper. All listed authors revised the paper and approved the final version of the article, including the authorship list. J.L. is the guarantor of this work and, as such, had full access to all the data in the study and takes responsibility for the integrity of the data and the accuracy of the data analysis.

\section{ADDITIONAL INFORMATION}

Competing interests: The authors declare no competing interests.

Ethics approval and consent to participate: The study was conducted conforming to the Declaration of Helsinki. According to the Swedish legislation (1998:543) on health data registries, informed consents were generally not needed for registrybased studies in Sweden if the studies had been approved by the local ethical board. ${ }^{43}$ This study was approved by Regional Ethical Review Board in Stockholm, Sweden (reference number 2016/982-3/4).

Consent for publication: Not applicable

Funding: This work was supported by Swedish Cancer Society (CAN 2015/460) and Swedish Research Council (SIMSAM D0547801). Both the founding resources were neither involved in the study design, data collection, data analysis and interpretation of the results nor in the writing of the report and in the decision to submit the article for publication.

Data availability: All the data in this study were retrieved from the Swedish Prescribed Drugs and Health Cohort. The original data are available from the related registries listed above but restrictions apply to the availability of these data, which were used under license for this study and therefore are not publicly available. The data are, however, available through applications to these registries or reasonable request to the corresponding author (S.X.). The codes for the data analysis are archived by the biostatistician (G.S.).

Note: This work is published under the standard license to publish agreement. After 12 months the work will become freely available and the license terms will switch to a Creative Commons Attribution 4.0 International (CC BY 4.0).

Publisher's note Springer Nature remains neutral with regard to jurisdictional claims in published maps and institutional affiliations.

\section{(1)}




\section{REFERENCES}

1. Fitzmaurice, C., Akinyemiju, T. F., Al Lami, F. H., Alam, T., Alizadeh-Navaei, R., Allen, C. et al. Global, Regional, and national cancer incidence, mortality, years of life lost, years lived with disability, and disability-adjusted life-years for 29 cancer groups, 1990 to 2016: a systematic analysis for the global burden of disease study. JAMA Oncol. 4, 1553-1568 (2018).

2. Balakrishnan, M., George, R., Sharma, A. \& Graham, D. Y. Changing trends in stomach cancer throughout the world. Curr. Gastroenterol. Rep. 19, 36 (2017).

3. Van Cutsem, E., Sagaert, X., Topal, B., Haustermans, K. \& Prenen, H. Gastric cancer. Lancet 388, 2654-2664 (2016).

4. Allemani, C., Weir, H. K., Carreira, H., Harewood, R., Spika, D., Wang, X.-S. et al. Global surveillance of cancer survival 1995-2009: analysis of individual data for 25676887 patients from 279 population-based registries in 67 countries (CONCORD-2). Lancet 385, 977-1010 (2015).

5. DeCensi, A., Puntoni, M., Goodwin, P., Cazzaniga, M., Gennari, A., Bonanni, B. et al. Metformin and cancer risk in diabetic patients: a systematic review and metaanalysis. Cancer Prev. Res. 3, 1451-1461 (2010).

6. Singh, S., Singh, H., Singh, P. P., Murad, M. H. \& Limburg, P. J. Antidiabetic medications and the risk of colorectal cancer in patients with diabetes mellitus: a systematic review and meta-analysis. Cancer Epidem. Biomark. 22, 2258-2268 (2013).

7. Zhang, Z. J., Zheng, Z. J., Shi, R., Su, Q., Jiang, Q. \& Kip, K. E. Metformin for liver cancer prevention in patients with type 2 diabetes: a systematic review and meta-analysis. J. Clin. Endocrinol. Metab. 97, 2347-2353 (2012).

8. Col, N. F., Ochs, L., Springmann, V., Aragaki, A. K. \& Chlebowski, R. T. Metformin and breast cancer risk: a meta-analysis and critical literature review. Breast Cancer Res. Treat. 135, 639-646 (2012).

9. Daugan, M., Dufay Wojcicki, A., d'Hayer, B. \& Boudy, V. Metformin: an anti-diabetic drug to fight cancer. Pharmacol. Res. 113(Pt A), 675-685 (2016).

10. Yu, G., Fang, W., Xia, T., Chen, Y., Gao, Y., Jiao, X. et al. Metformin potentiates rapamycin and cisplatin in gastric cancer in mice. Oncotarget 6, 12748-12762 (2015).

11. Chen, G., Feng, W., Zhang, S., Bian, K., Yang, Y., Fang, C. et al. Metformin inhibits gastric cancer via the inhibition of HIF1alpha/PKM2 signaling. Am. J. Cancer Res. 5, 1423-1434 (2015).

12. Courtois, S., Duran, R. V., Giraud, J., Sifre, E., Izotte, J., Megraud, F. et al. Metformin targets gastric cancer stem cells. Eur. J. Cancer 84, 193-201 (2017).

13. Zhou, X. L., Xue, W. H., Ding, X. F., Li, L. F., Dou, M. M., Zhang, W. J. et al. Association between metformin and the risk of gastric cancer in patients with type 2 diabetes mellitus: a meta-analysis of cohort studies. Oncotarget 8, 55622-55631 (2017).

14. Xie, S.-H., Santoni, G., Mattsson, F., Ness-Jensen, E. \& Lagergren, J. Cohort profile: the Swedish Prescribed Drugs and Health Cohort (SPREDH). BMJ Open 9, e023155 (2019).

15. Wettermark, B., Hammar, N., Fored, C. M., Leimanis, A., Otterblad Olausson, P., Bergman, U. et al. The new Swedish Prescribed Drug Register-opportunities for pharmacoepidemiological research and experience from the first six months. Pharmacoepidemiol. Drug Saf. 16, 726-735 (2007).

16. Wallerstedt, S. M., Wettermark, B. \& Hoffmann, M. The first decade with the swedish prescribed drug register-a systematic review of the output in the scientific literature. Basic Clin. Pharmacol. Toxicol. 119, 464-469 (2016).

17. Ekstrom, A. M., Signorello, L. B., Hansson, L. E., Bergstrom, R., Lindgren, A. \& Nyren, O. Evaluating gastric cancer misclassification: a potential explanation for the rise in cardia cancer incidence. J. Natl Cancer Inst. 91, 786-790 (1999).

18. Jakobsson, G. L., Sternegard, E., Olen, O., Myrelid, P., Ljung, R., Strid, H. et al. Validating inflammatory bowel disease (IBD) in the Swedish National Patient Register and the Swedish Quality Register for IBD (SWIBREG). Scand. J. Gastroenterol. 52, 216-221 (2017).

19. Ludvigsson, J. F., Andersson, E., Ekbom, A., Feychting, M., Kim, J. L., Reuterwall, C. et al. External review and validation of the Swedish national inpatient register. BMC Public Health 11, 450 (2011).

20. Brooke, H. L., Talback, M., Hornblad, J., Johansson, L. A., Ludvigsson, J. F., Druid, H. et al. The Swedish cause of death register. Eur. J. Epidemiol. 32, 765-773 (2017).

21. Charlson, M. E., Pompei, P., Ales, K. L. \& MacKenzie, C. R. A new method of classifying prognostic comorbidity in longitudinal studies: development and validation. J. Chronic Dis. 40, 373-383 (1987).

22. Doorakkers, E., Lagergren, J., Gajulapuri, V. K., Callens, S., Engstrand, L. \& Brusselaers, N. Helicobacter pylori eradication in the Swedish population. Scand. J. Gastroenterol. 52, 678-685 (2017).
23. Abnet, C. C., Freedman, N. D., Kamangar, F., Leitzmann, M. F., Hollenbeck, A. R. \& Schatzkin, A. Non-steroidal anti-inflammatory drugs and risk of gastric and oesophageal adenocarcinomas: results from a cohort study and a meta-analysis. Br. J. Cancer 100, 551-557 (2009).

24. Joo, M. K., Park, J. J. \& Chun, H. J. Additional benefits of routine drugs on gastrointestinal cancer: statins, metformin, and proton pump inhibitors. Dig. Dis. 36, 1-14 (2018).

25. Olefson, S. \& Moss, S. F. Obesity and related risk factors in gastric cardia adenocarcinoma. Gastric Cancer 18, 23-32 (2015).

26. Ekstrom, N., Schioler, L., Svensson, A. M., Eeg-Olofsson, K., Miao Jonasson, J., Zethelius, B. et al. Effectiveness and safety of metformin in 51675 patients with type 2 diabetes and different levels of renal function: a cohort study from the Swedish National Diabetes Register. BMJ Open 2, pii: e001076 (2012).

27. Steffen, A., Huerta, J. M., Weiderpass, E., Bueno-de-Mesquita, H. B., May, A. M., Siersema, P. D. et al. General and abdominal obesity and risk of esophageal and gastric adenocarcinoma in the European Prospective Investigation into Cancer and Nutrition. Int. J. Cancer. 137, 646-657 (2015).

28. Maclnnis, R. J., English, D. R., Hopper, J. L. \& Giles, G. G. Body size and composition and the risk of gastric and oesophageal adenocarcinoma. Int. J. Cancer. 118, 2628-2631 (2006)

29. Ruiter, R., Visser, L. E., van Herk-Sukel, M. P., Coebergh, J. W., Haak, H. R., GeelhoedDuijvestijn, P. H. et al. Lower risk of cancer in patients on metformin in comparison with those on sulfonylurea derivatives: results from a large populationbased follow-up study. Diabetes Care. 35, 119-124 (2012).

30. Hsieh, M. C., Lee, T. C., Cheng, S. M., Tu, S. T., Yen, M. H. \& Tseng, C. H. The influence of type 2 diabetes and glucose-lowering therapies on cancer risk in the Taiwanese. Exp. Diabetes Res. 2012, 413782 (2012).

31. Valent, F. Diabetes mellitus and cancer of the digestive organs: an Italian population-based cohort study. J. Diabetes Complicat. 29, 1056-1061 (2015).

32. Kim, Y. I., Kim, S. Y., Cho, S. J., Park, J. H., Choi, I. J., Lee, Y. J. et al. Long-term metformin use reduces gastric cancer risk in type 2 diabetics without insulin treatment: a nationwide cohort study. Aliment. Pharmacol. Ther. 39, 854-863 (2014).

33. Cheung, K. S., Chan, E. W., Wong, A. Y. S., Chen, L., Seto, W. K., Wong, I. C. K. et al. Metformin use and gastric cancer risk in diabetic patients after Helicobacter pylori eradication. J. Nat/ Cancer Inst. 111, 484-489 (2018).

34. Lee, M. S., Hsu, C. C., Wahlqvist, M. L., Tsai, H. N., Chang, Y. H. \& Huang, Y. C. Type 2 diabetes increases and metformin reduces total, colorectal, liver and pancreatic cancer incidences in Taiwanese: a representative population prospective cohort study of 800,000 individuals. BMC Cancer 11, 20 (2011).

35. Murff, H. J., Roumie, C. L., Greevy, R. A., Hackstadt, A. J., McGowan, L. E. D., Hung, A. M. et al. Metformin use and incidence cancer risk: evidence for a selective protective effect against liver cancer. Cancer Causes Control 29, 823-832 (2018).

36. Tseng, C. H. Metformin reduces gastric cancer risk in patients with type 2 diabetes mellitus. Aging (Albany N Y). 8, 1636-1649 (2016).

37. Jee, S. H., Ohrr, H., Sull, J. W., Yun, J. E., Ji, M. \& Samet, J. M. Fasting serum glucose level and cancer risk in Korean men and women. JAMA 293, 194-202 (2005).

38. Xu, H. L., Tan, Y. T., Epplein, M., Li, H. L., Gao, J., Gao, Y. T. et al. Population-based cohort studies of type 2 diabetes and stomach cancer risk in Chinese men and women. Cancer Sci. 106, 294-298 (2015).

39. Zheng, J., Rutegard, M., Santoni, G., Wallner, B., Johansson, I., Sund, M. et al. Prediabetes and diabetes in relation to risk of gastric adenocarcinoma. Br. J. Cancer 120, 1147-1152 (2019).

40. Yamagata, H., Kiyohara, Y., Nakamura, S., Kubo, M., Tanizaki, Y., Matsumoto, T. et al. Impact of fasting plasma glucose levels on gastric cancer incidence in a general Japanese population: the Hisayama study. Diabetes Care 28, 789-794 (2005).

41. Lin, S. W., Freedman, N. D., Hollenbeck, A. R., Schatzkin, A. \& Abnet, C. C. Prospective study of self-reported diabetes and risk of upper gastrointestinal cancers. Cancer Epidemiol. Biomarkers Prev. 20, 954-961 (2011).

42. Kim, T. J., Lee, H., Min, Y. W., Min, B. H., Lee, J. H., Son, H. J. et al. Diabetic biomarkers and the risk of proximal or distal gastric cancer. J. Gastroenterol. Hepatol. 31, 1705-1710 (2016)

43. Ludvigsson, J. F., Haberg, S. E., Knudsen, G. P., Lafolie, P., Zoega, H., Sarkkola, C. et al. Ethical aspects of registry-based research in the Nordic countries. Clin. Epidemiol. 7, 491-508 (2015) 